\title{
Spasmolytic effect of Acmella oleracea flowers extract on isolated rat ileum
}

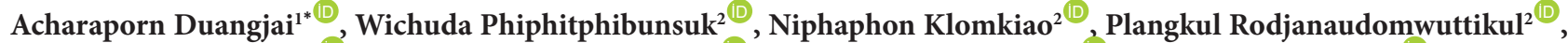 \\ Praewanit Ruangpoom $^{2}{ }^{\mathbb{D}}$, Sudarat Autthakitmongkol ${ }^{(\mathbb{D}}$, Atcharaporn Ontawong ${ }^{1}{ }^{\mathbb{D}}$, Nattakorn Kamkaew ${ }^{1 \mathbb{D}}$, Maleeruk \\ Utsintong $^{2,3} \mathbb{B}$, Surasak Saokaew ${ }^{2,3,4,5,6,7,8} \mathbb{D}$ \\ ${ }^{1}$ Unit of Excellence in Research and Product Development of Coffee, Division of Physiology, School of Medical Sciences, University of Phayao, Phayao, \\ Thailand \\ ${ }^{2}$ School of Pharmaceutical Sciences, University of Phayao, Phayao, Thailand \\ ${ }^{3}$ Unit of Excellence on Herbal Medicine, School of Pharmaceutical Sciences, University of Phayao, Phayao, Thailand \\ ${ }^{4}$ Center of Health Outcomes Research and Therapeutic Safety (Cohorts), School of Pharmaceutical Sciences, University of Phayao, Phayao, Thailand \\ ${ }^{5}$ Unit of Excellence on Clinical Outcomes Research and IntegratioN (UNICORN), School of Pharmaceutical Sciences, University of Phayao, Phayao, \\ Thailand \\ ${ }^{6}$ Division of Pharmacy Practice, Department of Pharmaceutical Care, School of Pharmaceutical Sciences, University of Phayao, Phayao, Thailand \\ ${ }^{7}$ Biofunctional Molecule Exploratory Research Group, Biomedicine Research Advancement Centre, School of Pharmacy, Monash University Malaysia, \\ Bandar Sunway, Selangor Darul Ehsan, Malaysia \\ ${ }^{8}$ Novel Bacteria and Drug Discovery Research Group, Microbiome and Bioresource Research Strength, Jeffrey Cheah School of Medicine and Health \\ Sciences, Monash University Malaysia, Bandar Sunway, Selangor Darul Ehsan, Malaysia
}

\section{A R T I C L E I N F O}

\section{Article Type:}

Original Article

\section{Article History:}

Received: 18 February 2020

Accepted: 1 June 2020

\section{Keywords:}

Acmella oleracea

Ileum

Rats

Relaxation

$\mathrm{CaCl}_{2}$

L-NAME

\begin{abstract}
A B S T R A C T
Introduction: Acmella oleracea has been used as a traditional medicine for treatment of asthma, sore throat, haemorrhoids and toothache. However, whether A. oleracea has gastrointestinal functions, such as regulation of intestinal contractions, has not been fully elucidated. Therefore, the aim of the present study was to investigate the effect of A. oleracea flowers extract (AFE) on rat ileum contractions and the possible mechanism(s) of its action.

Methods: The extract was prepared using the Soxhlet apparatus with 95\% ethanol. Ileum was removed from male Wistar rats and mounted in an organ bath containing Krebs solution. The tissue contractions were recorded by an isotonic transducer under $1 \mathrm{~g}$ tension.

Results: The cumulative concentrations of the AFE $(0.01-1 \mathrm{mg} / \mathrm{mL})$ reduced the ileum contractions induced by $\mathrm{KCl}(80 \mathrm{mM})(\mathrm{n}=6, P<0.05)$. AFE $(1 \mathrm{mg} / \mathrm{mL})$ attenuated the contractions induced by cumulative concentrations of $\mathrm{CaCl}_{2}(1-20 \mathrm{mM})$, while the spasmolytic effects of the extract were not reduced after tissue incubation with $\mathrm{N}(\omega)$-nitro-L-arginine methyl ester (L-NAME) (100 $\mu \mathrm{M}, 20$ minutes).

Conclusion: These results suggest that AFE inhibits ileum contractions without involving the nitric oxide pathway, which is possibly mediated via blockade of voltage-dependent calcium channels. A. oleracea may be useful in gastrointestinal disorders such as diarrhoea.
\end{abstract}

Implication for health policy/practice/research/medical education:

Acmella oleracea flowers extract exhibited spasmolytic activity by inhibiting $\mathrm{Ca}^{2+}$ influx, which may have implications for antispasmodic action in gastrointestinal disorders.

Please cite this paper as: Duangjai A, Phiphitphibunsuk W, Klomkiao N, Rodjanaudomwuttikul P, Ruangpoom P, Autthakitmongkol S, et al. Spasmolytic effect of Acmella oleracea flowers extract on isolated rat ileum. J Herbmed Pharmacol. 2021;10(1):109-115. doi: 10.34172/jhp.2021.11.

\section{Introduction}

Irritable bowel syndrome (IBS) is a functional gastrointestinal disorder characterised by abdominal pain, an alteration in bowel habits and flatulence (1). The global prevalence of IBS in adults ( $\geq 15$ years old) is estimated to be $11.2 \%$ (95\% confidence interval [CI], 9.8-12.8\%) (2). The severity of IBS is associated with the healthrelated quality of life of patients (3). Various medications 
are used for IBS treatment, including anti-spasmodic drugs (smooth muscle relaxants and calcium channel blockers), bulking agents and anti-diarrheal agents (1). As IBS is a long-term gastrointestinal disorder with recurring symptoms and an increased financial burden, herbal medicine is considered as an alternative treatment for the gastrointestinal symptoms of IBS. Herbs used for IBS management, including Mentha piperita, Aloe vera, Curcuma longa, Fumaria officinalis, and Hypericum perforatum, play a role in controlling abdominal pain, have prosecretory and anti-inflammatory activities, and regulate gastrointestinal motility (4).

Acmella oleracea (L.) R.K. Jansen (Spilanthes acmella Murr. or Spilanthes oleracea L. or Acmella uliginosa (SW.) Cass) is a part of the Asteraceae family. A. oleracea is found in tropical and subtropical areas of Asia, Africa and South America, and is commonly used in local cuisine and folk medicine (5). A. oleracea contains alkylamides, phenolic compounds, coumarins, triterpenoids (6), phytosterols, tannins (7), polysaccharides and rhamnogalacturonan (8). It has a variety of pharmacological properties, including antioxidant, antimicrobial (6), antiulcerogenic (9), diuretic (10), anaesthetic, antifungal, antimalarial, larvicidal, antipyretic, bioinsecticidal, anticonvulsant, analgesic, pancreatic lipase inhibitor and antiinflammatory activities (5). In addition, A. oleracea shows vasorelaxant potential in rat thoracic aorta (11). However, the spasmolytic effect of A. oleracea in intestinal smooth muscle is not well understood. The present study investigates the relaxant effect of $A$. oleracea on ileum contractions and its possible mechanism.

\section{Materials and Methods}

Chemicals

Folin-Ciocalteu's phenol reagent, N ( $\omega)$-nitro-L-arginine methyl ester (L-NAME), and quercetin were bought from Sigma-Aldrich. EGTA and HEPES were purchased from Bio Basic Canada Inc. (Ontario, Canada). Xylazine was obtained from L.B.S. Laboratory LTD. (Bangkok, Thailand), Zoletil 50 was purchased from VIRBAC Laboratories (Carros, France). Dimethylsulphoxide and methanol were obtained from RCI Labscan. $\mathrm{KCl}, \mathrm{CaCl}_{2}$ and other reagents were obtained from Ajax Finechem. The Krebs solution, $\mathrm{pH} 7.3$ was prepared with the following composition (in mM): $\operatorname{HEPES}$ (10), $\mathrm{NaCl}$ (122), $\mathrm{KCl}(5), \mathrm{KH}_{2} \mathrm{PO}_{4}(0.5), \mathrm{NaH}_{2} \mathrm{PO}_{4}(0.5), \mathrm{MgCl}_{2}(1), \mathrm{CaCl}_{2}$ (1.8), and glucose (11).

\section{Plant materials and extraction}

Acmella oleracea flowers were collected from Jam Pa Wai village, Phayao province, Thailand. The collected specimen was identified using key and description form taxonomic literatures, Flora of China and research papers. A voucher specimen was deposited at the Forest Herbarium (BKF), Royal Forest Department, the Ministry of Agriculture,
Thailand (Collection number: WPAc041). For the extraction, flowers were washed, dried and powdered finely. The A. oleracea flowers extract (AFE) was prepared by placing $4 \mathrm{~g}$ of dry flowers with $95 \%$ ethanol $(300 \mathrm{~mL}$ ) in a Soxhlet extractor for 4 hours. Then, it was filtered and evaporated on a rotary evaporator. The extract was kept at $-20^{\circ} \mathrm{C}$ until used.

Determination of total phenolic content

Total phenolic content of the extract was determined by the Folin-Ciocalteu method. Accordingly, $10 \mathrm{mg}$ of the extract was dissolved in $1 \mathrm{~mL}$ of DMSO. A total of 250 $\mu \mathrm{L}$ of the extract was mixed with $10 \%$ Folin-Ciocalteu reagent $(1 \mathrm{~mL})$ for 5 minutes, and then $800 \mu \mathrm{L}$ of $7.5 \%$ $\mathrm{NaCO}_{3}$ was added to the mixed solution. The absorbance was measured at $765 \mathrm{~nm}$ after 20 minutes of incubation in the dark. The results were expressed as mg gallic acid equivalent (GAE)/g extract (12).

Determination of total flavonoid content

Total flavonoid content of the extract was determined by the aluminium chloride colorimetric method (13). Briefly, $250 \mu \mathrm{L}$ of the extract $(0.1 \mathrm{mg} / \mathrm{mL})$ was mixed with 1.25 $\mathrm{mL}$ of distilled water, $0.1 \mu \mathrm{L}$ of $10 \% \mathrm{AlCl}_{3}$, and $75 \mu \mathrm{L}$ of $5 \%$ $\mathrm{NaNO}_{2}$ for 6 minutes. Then, $150 \mu \mathrm{L}$ of $10 \% \mathrm{AlCl}_{3} \cdot 6 \mathrm{H}_{2} \mathrm{O}$ was added for 5 minutes and $500 \mu \mathrm{L}$ of $1 \mathrm{M} \mathrm{NaOH}$ was added. The absorbance of the reaction mixture was measured at $510 \mathrm{~nm}$. The total flavonoid content was expressed as mg catechin equivalent (CE)/g extract.

\section{HPLC analysis}

High performance liquid chromatography (HPLC) was performed in a HPLC system (Shimadzu - LC-20A). Extract was prepared in HPLC grade ethanol. Then, the sample was sonicated using an ultrasonicator for 15 minutes and detection was performed at $292 \mathrm{~nm}$ and 370 $\mathrm{nm}$. Naringin and quercetin were used as the standards and ran under wavelength at $292 \mathrm{~nm}$ and $370 \mathrm{~nm}$, respectively. All solutions were filtered through a 0.45 $\mu \mathrm{m}$. The separation was carried out with the flow rate 1 $\mathrm{mL} / \mathrm{min}$ using an Inertsil ODS-3 $(150 \times 4.6 \mathrm{~mm})$ column and using a mobile phase of 3:1 (methanol- $\left.\mathrm{H}_{2} \mathrm{O}\right)$ with an injection volume of $20 \mu \mathrm{L}$ for 20 minutes.

\section{Animal and ileum preparation}

Male Wistar rats (bred at the National Laboratory Animal Centre, Salaya, Phutthamonthon, Nakhon Pathom, Mahidol University) weighing 200-250 g were housed under the controlled conditions of temperature $\left(22 \pm 2^{\circ} \mathrm{C}\right)$, light/dark cycle (12/12 hours) and were fed a standard chow diet. All procedures were carried out in accordance with the Animal Ethics Committee of the University of Phayao, Phayao, Thailand (Ethic NO. 610204001). After overnight fasting, rats were deeply anaesthetised with Zoletil (50 mg/kg BW) and xylazine (3 mg/kg BW). 
Isolation of rat ileum

Ileum was isolated rapidly, and the mesentery and fatty tissue were removed and then flushed clean with Krebs solution. A $1.5 \mathrm{~cm}$ length of ileum was transferred to an organ bath containing $30 \mathrm{~mL}$ Krebs solution at room temperature, $\mathrm{pH} 7.4,95 \% \mathrm{O}_{2}$ and $5 \% \mathrm{CO}_{2}$ and placed under $1 \mathrm{~g}$ tension. The tissue was equilibrated for 1 hour and washed every 15 minutes prior to the experiment. Isotonic responses were recorded using a force transducer and an iWorx $214 \mathrm{~A} / \mathrm{D}$ converter (LabScribe2; Instruments, Thailand).

Relaxant effect on $\mathrm{K}^{+}$-induced ileum contractions To find out whether $A$. oleracea extract induced ileum relaxation, cumulative doses of the extract were administered. After the ileum stabilisation period, contraction was evoked by $\mathrm{KCl}(80 \mathrm{mM})$ for induction of maximum contractions. Then, the extracts were added cumulatively $(0.01-1 \mathrm{mg} / \mathrm{mL})$ in an organ bath, and the isometric contractions were measured.

Characterisation of the relaxation effect of the extract on calcium influx

In order to investigate the relaxant effect of $A$. oleracea extract with regard to calcium influx regulation, $\mathrm{Ca}^{2+}$-free Krebs solution was used. After contraction of the ileum was abolished in the $\mathrm{Ca}^{2+}$-free solution, with the following composition (mM): EGTA (0.01), $\mathrm{NaCl}$ (122), $\mathrm{KCl}$ (5), HEPES (10), $\mathrm{KH}_{2} \mathrm{PO}_{4}(0.5), \mathrm{NaH}_{2} \mathrm{PO}_{4}(0.5), \mathrm{MgCl}_{2}$ (1), and glucose (11) with $\mathrm{pH} 7.3$ for 30 minutes, a cumulative concentration of $\mathrm{Ca}^{2+}(1-20 \mathrm{mM})$ was added in the bath containing high $\mathrm{K}^{+}$solution in the absence or in the presence of the extract $(1 \mathrm{mg} / \mathrm{mL})$.

Characterisation of the relaxation effect of the extract on acetylcholine pathway

To investigate the role of $A$. oleracea extract involving the acetylcholine pathway, acetylcholine chloride was used to mimic the effects of acetylcholine. The tissue was incubated either in the presence or in the absence of the extract $(1 \mathrm{mg} / \mathrm{mL})$ or atropine $(100 \mathrm{nM})$ in an organ bath for 20 minutes before acetylcholine chloride-induced $\left(10^{-3}\right.$ $\mathrm{mM}$, agonist of acetylcholine receptor) contractions.

Characterisation of the relaxation effect of the extract on nitric oxide pathway

In order to determine whether the extract had a relaxation effect through the nitric oxide pathway, the extract (1 $\mathrm{mg} / \mathrm{mL}$ ) in the absence or in the presence of L-NAME at $100 \mathrm{mM}$ (antagonist of nitric oxide synthase) was added in the bath for 20 minutes before $\mathrm{KCl}$ - induced contractions. Ileum contractions were calculated as a percentage of the contractile response.

Statistical analysis

The results are shown as mean \pm standard error of the mean (SEM). Statistical analyses were analysed using paired two-tailed Student's $t$ test. $P$ value less than 0.05 was considered statistically significant.

Results

HPLC analysis of Acmella oleracea extract

Acmella oleracea extract was dissolved in HPLC grade ethanol and analysed by HPLC system, using methanol and water as the mobile phase in the ratio of $3: 1(\mathrm{v} / \mathrm{v})$. Quercetin and naringin were used as the standards. HPLC chromatograms of all the standard mixtures were recorded at $272 \mathrm{~nm}$ and $370 \mathrm{~nm}$. The retention time of quercetin and naringin were found at 3.4 minutes and 1.97 minutes, respectively. HPLC revealed the amount of quercetin to be $7.6 \mathrm{mg} / \mathrm{g}$ and naringin to be $2.4 \mathrm{mg} / \mathrm{g}$ as shown in Figure 1 .

Total phenolic and flavonoid contents

Total phenolic and flavonoid contents were reported as GAE by reference to the standard curve $(y=0.0247 x$ - 0.0043; $\mathrm{R}^{2}=0.998$ ) and catechin equivalents (CE) by reference to the standard curve $(\mathrm{y}=0.0947 \mathrm{x}+0.0412$; $\left.\mathrm{R}^{2}=0.998\right)$, respectively. The $A$. oleracea extract had a total phenolic content of $4.32 \pm 0.07 \mathrm{mg}$ GAE/g of dry extract and a total flavonoid content of $22.15 \pm 3.62 \mathrm{mg} \mathrm{CE} / \mathrm{g}$ of dry extract.

Effect of Acmella oleracea extract on $\mathrm{KCl}$-induced ileal contractions

The spasmolytic effects of $A$. oleracea extract on spontaneous contractions of the ileum are shown in Figure 2. Cumulative concentrations of the extract $(0.01-1 \mathrm{mg} /$ $\mathrm{mL})$ significantly reduced the ileum contractions induced by $\mathrm{KCl}(80 \mathrm{mM})$, in a dose-dependent manner.

Spasmolytic effect of Acmella oleracea extract on $\mathrm{Ca}^{2+}$ induced contractions

In order to characterise the spasmolytic effect of $A$. oleracea extract involved in interfering with extracellular $\mathrm{Ca}^{2+}$ influx, cumulative concentrations of $\mathrm{CaCl}_{2}$ (1-20 $\mathrm{mM}$ ) were used to induced contractions in the presence and in the absence of the extract $(1 \mathrm{mg} / \mathrm{mL})$. In the presence of the extract, a diminished response in ileum contractions was induced by $\mathrm{CaCl}_{2}$ as shown in Figure 3 . This result suggests that $A$. oleracea extract might interfere with calcium influx or block the calcium channel.

Spasmolytic effect of Acmella oleracea extract in the presence of L-NAME

Nitric oxide is known to induce intestinal smooth muscle relaxation. To explore the spasmolytic effect of $A$. oleracea extract mediated by the nitric oxide pathway, L-NAME (100 $\mu \mathrm{M}$, antagonist of nitric oxide synthase) was used as a pre-treatment for 20 minutes before the A. oleracea extract was added. The spasmolytic effect of the extract $(1 \mathrm{mg} /$ $\mathrm{mL}$ ) on $\mathrm{KCl}$ - induced ileum contractions was unaffected by L-NAME as shown in Figure 4. 

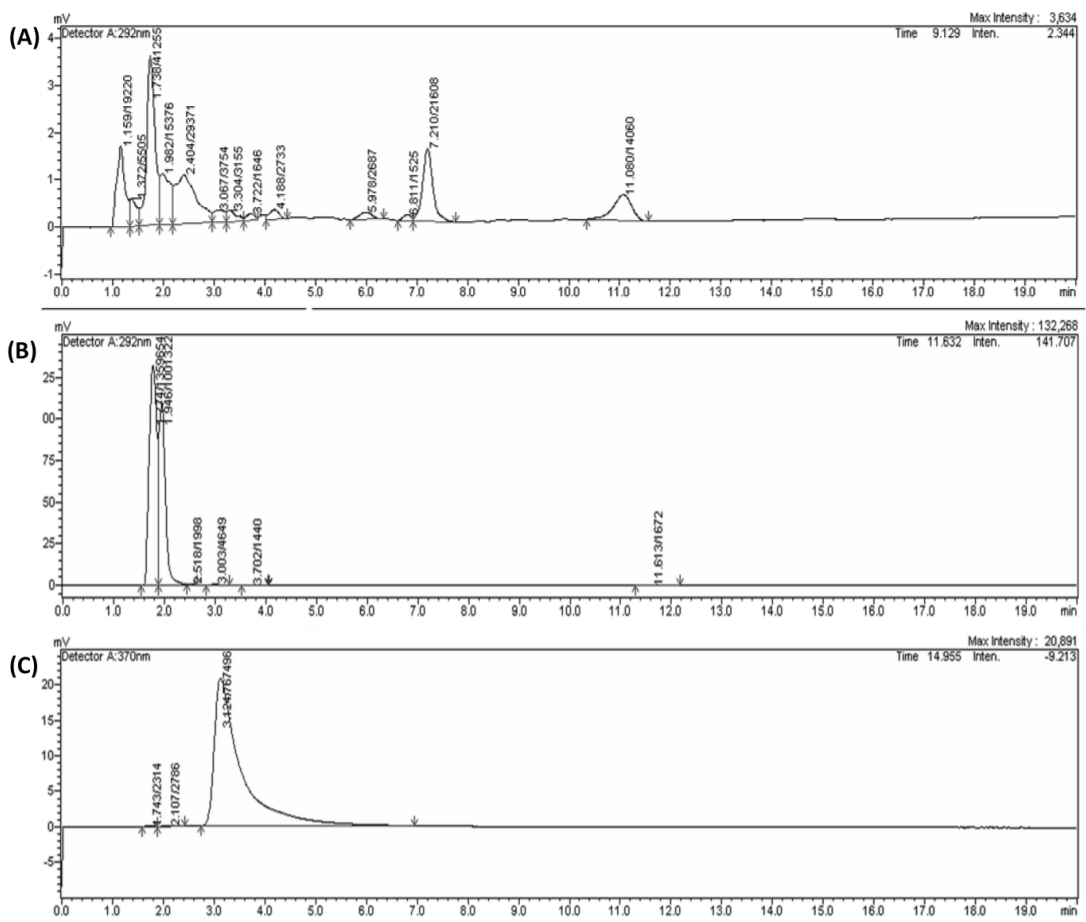

Figure 1. HPLC chromatograms of Acmella oleracea (A) naringin (B) and quercetin (C) at $292 \mathrm{~nm}$ and $370 \mathrm{~nm}$.

Spasmolytic effect of Acmella oleracea extract in the presence of acetylcholine

To examine the spasmolytic effect of $A$. oleracea extract through a cholinergic mechanism, acetylcholine chloride $\left(10^{-3} \mathrm{mM}\right)$ was added in the organ bath after tissue treatment with the extract $(1 \mathrm{mg} / \mathrm{mL})$ or atropine $(100$ $\mathrm{nM}$ ) for 20 minutes. The extract and atropine abolished the response to acetylcholine as shown in Figure 5.

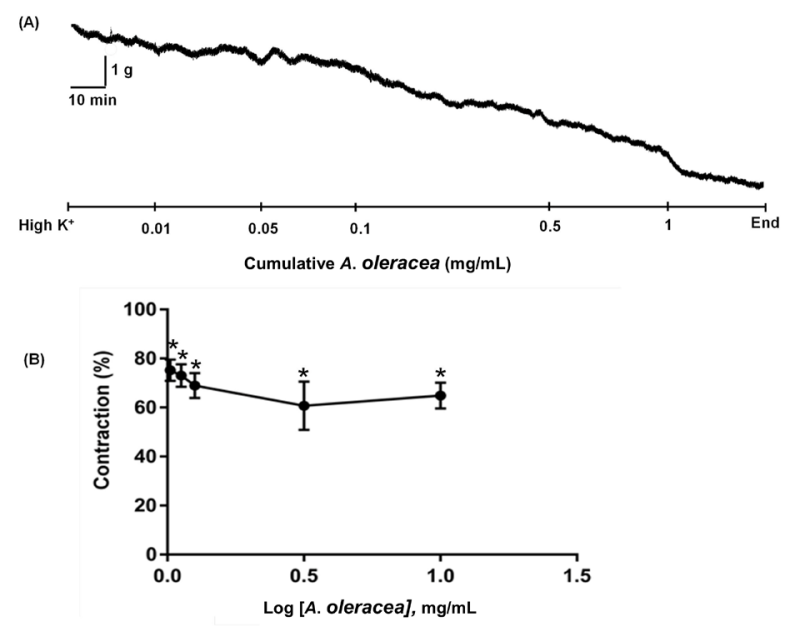

Figure 2. A typical trace of effect of Acmella oleracea extract (0.01-1 mg/ $\mathrm{mL}$ ) on ileum contractions induced by $\mathrm{KCl}(80 \mathrm{mM})(\mathrm{A})$. Spasmolytic effect of cumulative concentrations of Acmella oleracea extract on $\mathrm{KCl}$-induced rat ileum contractions $(n=6)(B)$. The responses are expressed as the percentage of initial contractions elicited by $\mathrm{KCl}$. Values were considered to be significantly different from control when $P<0.05$.

\section{Discussion}

This study demonstrated the spasmolytic effect of AFE in isolated rat ileum due to its ability to cause ileal smooth muscle relaxation by blocking voltage-dependent calcium channels. Intestinal smooth muscle contraction is mediated mainly via increased intracellular $\mathrm{Ca}^{2+}$ concentration $(14,15)$. Furthermore, high levels of $\mathrm{K}^{+}$ result in smooth muscle membrane depolarisation that

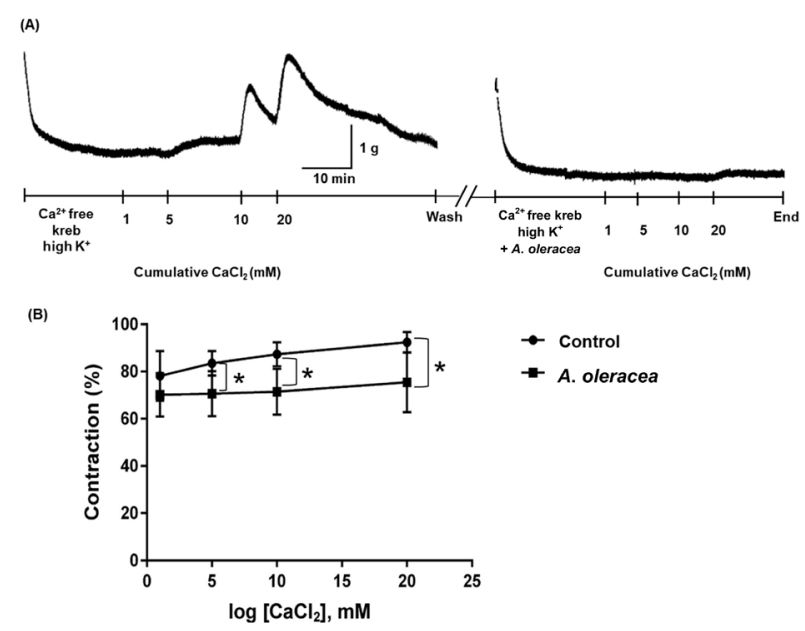

Figure 3. Cumulative concentration-response curves to $\mathrm{CaCl}_{2}$ in both absence (A) and presence (B) of Acmella oleracea extract $(1 \mathrm{mg} / \mathrm{mL})$ on rat ileum $(n=6)$. The responses are expressed as the percentage of initial contractions elicited by $\mathrm{CaCl}_{2}$. Differences were considered statistically significant $(P<0.05)$ compared with the control. 


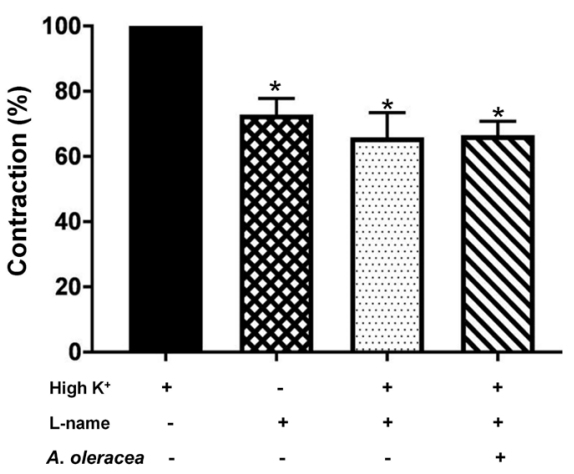

Figure 4. Effect of Acmella oleracea extract $(1 \mathrm{mg} / \mathrm{mL})$ on the $\mathrm{KCl}$ induced rat ileum contractions in the absence and in the presence of L-NAME. Data is expressed as mean \pm SEM of six experiments. * indicates significant differences $(P<0.001)$ compared with the high $\mathrm{K}^{+}$ group.

activates L-type voltage-dependent $\mathrm{Ca}^{2+}$ channels, which mediate $\mathrm{Ca}^{2+}$ influx to trigger a sustained contraction (16, 17). It has been suggested that blockers of $\mathrm{Ca}^{2+}$ influx can inhibit high $\mathrm{K}^{+}$-induced smooth muscle contraction (18).

The current study demonstrated that AFE contains quercetin and naringin 7.6 and $2.4 \mathrm{mg} / \mathrm{g}$ extract, respectively. In addition, AFE-rich quercetin relaxed ileal smooth muscle by blocking $\mathrm{Ca}^{2+}$ influx. Consistent with these findings, a previous in vivo study showed that quercetin had an effect on intestinal muscle relaxation in high $\mathrm{K}^{+}$-induced rat intestinal contractions (19). Moreover, quercetin showed an inhibitory effect on the spontaneous contractions of rabbit duodenum (20) and also inhibited intestinal contractions induced by different concentrations of calcium, indicating a calciumantagonistic effect (21). Moreover, Polygonum aviculare L.-rich quercetin inhibits L-type voltage-dependent $\mathrm{Ca}^{2+}$ channels, resulting in attenuation of airway smooth muscle contraction (22). However, there are several studies that have shown quercetin activates L-type calcium channels, resulting in increased $\mathrm{Ca}^{2+}$ influx into cells $(23,24)$. Thus, the effect of quercetin on L-type voltage-dependent $\mathrm{Ca}^{2+}$ channels may be different in each type of tissue.

Acetylcholine(Ach) isagastrointestinalneurotransmitter that increases intestinal muscle contraction by activating $M_{3}$ muscarinic receptors (25). Activation of the $M_{3}$ receptor leads to the stimulation of $\mathrm{Ca}^{2+}$ influx into cells by activating phospholipase $\mathrm{C}$, inositol trisphosphate and diacylglycerol $(26,27)$. In addition, Ach can also activate $\mathrm{Ca}^{2+}$ channels, short transient receptor potential channel 3 and stromal interaction molecule (STIM)/Orai channels $(28,29)$. Several studies have reported that spasmolytic plants can be non-competitive antagonists of Ach in duodenal or ileal smooth muscle (30-32).

This study clearly demonstrated the effect of AFE on isolated rat ileum, as it markedly inhibited rat ileum contractions similar to atropine and was a competitive

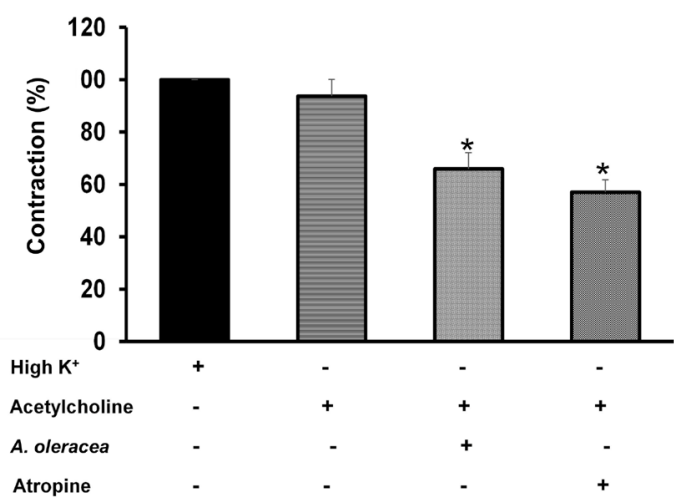

Figure 5. Effect of Acmella oleracea extract $(1 \mathrm{mg} / \mathrm{mL})$ on the $\mathrm{KCl}$ induced rat ileum contractions in the absence and in the presence of acetylcholine $(n=6)$. Data is expressed as mean \pm SEM. * indicates significant differences $(P<0.001)$ compared with the high $\mathrm{K}^{+}$group.

antagonist of Ach. The relaxant effect of AFE may be due to its antagonistic effect on muscarinic receptors and/or $\mathrm{Ca}^{2+}$ channels in ileal smooth muscle cells. Therefore, this study suggests that there is a great potential for developing AFE into a herbal medicine and/or a nutraceutical product.

\section{Conclusion}

This study demonstrated, for the first time, AFE's effective spasmolytic property on isolated rat ileum by inhibiting $\mathrm{Ca}^{2+}$ influx into intestinal smooth muscle. Thus, AFE has great potential as a nutraceutical product/herbal medicine for its overall antispasmodic action in gastrointestinal disorders such as diarrhoea.

\section{Acknowledgements}

We would like to thank the School of Medical Sciences, University of Phayao for providing the facilities to conduct the research.

\section{Authors' contribution}

AD contributed in designing the study and supervising and editing the manuscript. NK, PR, PR and SA performed and analysed the data. $\mathrm{AD}$ and $\mathrm{AO}$ prepared the manuscript. All authors read and confirmed the manuscript.

\section{Conflict of interests}

The authors declare that there is no conflict of interests regarding the publication of this paper.

\section{Ethical considerations}

Ethical issues (including plagiarism, misconduct, data fabrication, falsification, double publication or submission) have been carefully checked by authors. The handling with animals were carried out in accordance the Animal Ethics Committee of the University of Phayao, Phayao, Thailand (Ethic NO. 610204001). 


\section{Funding/Support}

This research was partially supported by Unit of Excellence on Clinical Outcomes Research and IntegratioN (UNICORN), School of Pharmaceutical Sciences, [grant number UoE62003], and Unit of Excellence in Research and Product Development of Coffee [grant number UoE62007 and UoE63004], University of Phayao, and the NSTDA Chair Professor Grant (the Fourth Grant) of the Crown Property Bureau Foundation and the National Science and Technology Development Agency to Professor Dr. Vatcharin Rukachaisirikul.

\section{References}

1. Vahedi H, Ansari R, Mir-Nasseri M, Jafari E. Irritable bowel syndrome: a review article. Middle East J Dig Dis. 2010;2(2):66-77.

2. Lovell RM, Ford AC. Global prevalence of and risk factors for irritable bowel syndrome: a meta-analysis. Clin Gastroenterol Hepatol. 2012;10(7):712-21.e4. doi: 10.1016/j.cgh.2012.02.029.

3. Mönnikes H. Quality of life in patients with irritable bowel syndrome. J Clin Gastroenterol. 2011;45 Suppl:S98-101. doi: 10.1097/MCG.0b013e31821fbf44.

4. Bahrami HR, Hamedi S, Salari R, Noras M. Herbal medicines for the management of irritable bowel syndrome: a systematic review. Electron Physician. 2016;8(8):2719-25. doi: $10.19082 / 2719$.

5. Dubey S, Maity S, Singh M, SarafSA, Saha S. Phytochemistry, pharmacology and toxicology of Spilanthes acmella: a Review. Adv Pharmacol Sci. 2013;2013:423750. doi: $10.1155 / 2013 / 423750$.

6. Prachayasittikul S, Suphapong S, Worachartcheewan A, Lawung R, Ruchirawat S, Prachayasittikul V. Bioactive metabolites from Spilanthes acmella Murr. Molecules. 2009;14(2):850-67. doi: 10.3390/molecules14020850.

7. Lalthanpuii $\mathrm{PB}$, Lalawmpuii $\mathrm{R}$, Vanlaldinpuia $\mathrm{K}$, Lalchhandama K. Phytochemical investigations on the medicinal plant Acmella oleracea cultivated in Mizoram, India. Science Vision. 2016;16(4):177-83.

8. Nascimento AM, de Souza LM, Baggio CH, Werner MF, Maria-Ferreira D, da Silva LM, et al. Gastroprotective effect and structure of a rhamnogalacturonan from Acmella oleracea. Phytochemistry. 2013;85:137-42. doi: 10.1016/j. phytochem.2012.08.024.

9. Maria-Ferreira D, da Silva LM, Mendes DA, de Almeida Cabrini D, Nascimento AM, Iacomini M, et al. Rhamnogalacturonan from Acmella oleracea (L.) R.K. Jansen: gastroprotective and ulcer healing properties in rats. PLoS One. 2014;9(1):e84762. doi: 10.1371/journal. pone. 0084762 .

10. Ratnasooriya WD, Pieris KP, Samaratunga U, Jayakody JR. Diuretic activity of Spilanthes acmella flowers in rats. J Ethnopharmacol. 2004;91(2-3):317-20. doi: 10.1016/j. jep.2004.01.006.

11. Wongsawatkul O, Prachayasittikul S, Isarankura-NaAyudhya C, Satayavivad J, Ruchirawat S, Prachayasittikul V. Vasorelaxant and antioxidant activities of Spilanthes acmella Murr. Int J Mol Sci. 2008;9(12):2724-44. doi: 10.3390/ijms9122724.
12. Singleton VL, Rossi JA. Colorimetry of total phenolics with phosphomolybdic-phosphotungstic acid reagents. Am J Enol Vitic. 1965;16(3):144-58.

13. Zhishen J, Mengcheng T, Jianming W. The determination of flavonoid contents in mulberry and their scavenging effects on superoxide radicals. Food Chem. 1999;64(4):555-9. doi: 10.1016/S0308-8146(98)00102-2.

14. Ma T, Qi QH, Yang WX, Xu J, Dong ZL. Contractile effects and intracellular Ca2+ signalling induced by emodin in circular smooth muscle cells of rat colon. World J Gastroenterol. 2003;9(8):1804-7. doi: 10.3748/wjg. v9.i8.1804.

15. Hill-Eubanks DC, Werner ME, Heppner TJ, Nelson MT. Calcium signaling in smooth muscle. Cold Spring Harb Perspect Biol. 2011;3(9):a004549. doi: 10.1101/cshperspect. a004549.

16. Borrelli F, Capasso F, Capasso R, Ascione V, Aviello G, Longo R, et al. Effect of Boswellia serrata on intestinal motility in rodents: inhibition of diarrhoea without constipation. Br J Pharmacol. 2006;148(4):553-60. doi: 10.1038/sj.bjp.0706740.

17. Kaya TT, Koyluoglu G, Soydan AS, Arpacik M, Karadas B. Effects of nimesulide and pentoxifylline on decreased contractile responses in rat ileum with peritonitis. Eur J Pharmacol. 2002;442(1-2):147-53. doi: 10.1016/s00142999(02)01509-1.

18. Gilani AH, Bashir S, Janbaz KH, Shah AJ. Presence of cholinergic and calcium channel blocking activities explains the traditional use of Hibiscus rosasinensis in constipation and diarrhoea. J Ethnopharmacol. 2005;102(2):289-94. doi: 10.1016/j.jep.2005.07.023.

19. Ragone MI, Sella M, Conforti P, Volonté MG, Consolini AE. The spasmolytic effect of Aloysia citriodora, Palau (South American cedrón) is partially due to its vitexin but not isovitexin on rat duodenums. J Ethnopharmacol. 2007;113(2):258-66. doi: 10.1016/j.jep.2007.06.003.

20. Santos-Fagundes D, Grasa L, Gonzalo S, Valero MS, Castro M, Arruebo MP, et al. Different mechanisms of actions of genistein, quercetin on spontaneous contractions of rabbit duodenum. Rev Esp Enferm Dig. 2015;107(7):413-6. doi: 10.17235/reed.2015.3695/2015.

21. Morales MA, Tortoriello J, Meckes M, Paz D, Lozoya X. Calcium-antagonist effect of quercetin and its relation with the spasmolytic properties of Psidium guajava L. Arch Med Res. 1994;25(1):17-21.

22. Luo X, Xue L, Xu H, Zhao QY, Wang Q, She YS, et al. Polygonum aviculare L. extract and quercetin attenuate contraction in airway smooth muscle. Sci Rep. 2018;8(1):3114. doi: 10.1038/s41598-018-20409-x.

23. Bardy G, Virsolvy A, Quignard JF, Ravier MA, Bertrand G, Dalle S, et al. Quercetin induces insulin secretion by direct activation of L-type calcium channels in pancreatic beta cells. Br J Pharmacol. 2013;169(5):1102-13. doi: 10.1111/ bph.12194.

24. Saponara S, Sgaragli G, Fusi F. Quercetin as a novel activator of L-type $\mathrm{Ca}(2+)$ channels in rat tail artery smooth muscle cells. Br J Pharmacol. 2002;135(7):1819-27. doi: 10.1038/ sj.bjp.0704631.

25. Eglen RM, Hegde SS, Watson N. Muscarinic receptor subtypes and smooth muscle function. Pharmacol Rev. 
1996;48(4):531-65.

26. Candell LM, Yun SH, Tran LL, Ehlert FJ. Differential coupling of subtypes of the muscarinic receptor to adenylate cyclase and phosphoinositide hydrolysis in the longitudinal muscle of the rat ileum. Mol Pharmacol. 1990;38(5):689-97.

27. Prestwich SA, Bolton TB. G-protein involvement in muscarinic receptor-stimulation of inositol phosphates in longitudinal smooth muscle from the small intestine of the guinea-pig. Br J Pharmacol. 1995;114(1):119-26. doi: 10.1111/j.1476-5381.1995.tb14915.x.

28. Zhang CH, Lifshitz LM, Uy KF, Ikebe M, Fogarty KE, ZhuGe R. The cellular and molecular basis of bitter tastantinduced bronchodilation. PLoS Biol. 2013;11(3):e1001501. doi: 10.1371/journal.pbio.1001501.

29. Zhang T, Luo XJ, Sai WB, Yu MF, Li WE, Ma YF, et al. Nonselective cation channels mediate chloroquine-induced relaxation in precontracted mouse airway smooth muscle. PLoS One. 2014;9(7):e101578. doi: 10.1371/journal. pone. 0101578 .

30. Câmara CC, Nascimento NR, Macêdo-Filho CL, Almeida FB, Fonteles MC. Antispasmodic effect of the essential oil of Plectranthus barbatus and some major constituents on the guinea-pig ileum. Planta Med. 2003;69(12):1080-5. doi: 10.1055/s-2003-45186.

31. Karamenderes C, Apaydin S. Antispasmodic effect of Achillea nobilis L. subsp. sipylea (O. Schwarz) Bässler on the rat isolated duodenum. J Ethnopharmacol. 2003;84(23):175-9. doi: 10.1016/s0378-8741(02)00296-9.

32. Sánchez de Rojas VR, Ortega T, Villar A. Inhibitory effects of Cistus populifolius on contractile responses in the isolated rat duodenum. J Ethnopharmacol. 1995;46(1):59-62. doi: 10.1016/0378-8741(95)01229-7. 